\title{
Interrelationships of the North Atlantic multidecadal climate variability characteristics
}

\author{
Roman V. Bekryaev ${ }^{1,2}$
}

Received 23 October 2018; accepted 30 November 2018; published 3 June 2019.

The North Atlantic is one of the key regions, where low-frequency climate variability is formed. However, despite numerous studies related to this topic, some issues still remains unsolved. One of them is the ambiguous cross-correlation of the North Atlantic sea surface temperature (SST) and the intensity of Atlantic Meridional Overturning Circulation (AMOC). A widely accepted concept suggests that the long-term climate variability is a result of the atmospheric stochastic forcing transformed by the inertial ocean. Existence of negative and positive feedback mechanisms suggests that the long-term North Atlantic dynamics may be considered as a damped stochastically forced oscillator in which both SST and AMOC are the elements of the same process. In this study, we analyze the cross-correlation functions of the main North Atlantic climatic indexes derived from a simple box-like stochastic model. The random forcing simulates the air-sea interface heat fluxes and excites both the SST and the AMOC. Stochastic excitation of the meridional circulation implies the leading AMOC and stochastic forcing of SST implies the leading Atlantic Multidecadal Oscillation (AMO). Connection of the AMOC and AMO indexes depends on the principal oceanic feedbacks and the dissipation intensity. KEYWORDS: North Atlantic; stochastic forcing; variability; Atlantic Multidecadal Oscillation; cross-correlation.

Citation: Bekryaev, Roman V. (2019), Interrelationships of the North Atlantic multidecadal climate variability characteristics, Russ. J. Earth. Sci., 19, ES3004, doi:10.2205/2018ES000653.

\section{Introduction}

One of the key regions where the climate multidecadal variability (MDV) originates is the North Atlantic. The most impressive example of longterm changes may be related to the Atlantic Multidecadal Oscillation. The AMO index is defined by spatially averaged detrended anomalies of the North Atlantic SST [Enfield et al., 2001; Knight et al., 2005, 2006. However, there are some stud-

\footnotetext{
${ }^{1}$ Earth Science Institute, St. Petersburg State University, St. Petersburg, Russia

${ }^{2}$ Voeikov Main Geophysical Observatory, St. Petersburg, Russia

Copyright 2019 by the Geophysical Center RAS. http://rjes.wdcb.ru/doi/2018ES000653-res.html
}

ies which use slightly different AMO definition, e.g. [d'Orgeville and Peltier, 2007: Trenberth and Shea, 2006 .

The North Atlantic SST variability is closely connected to dynamics of the large-scale oceanic components, such as AMOC and Subpolar Gyre (SPG). The AMOC plays an important role in the meridional oceanic heat transfer. The largest Atlantic meridional energy transport reaches $\sim$ $1.2 \mathrm{PW}$ across $26^{\circ} \mathrm{N}$ [Johns et al., 2011, Ushakov and Ibrayev, 2018.

The leading role of low-frequency variability with the scale of 50-80 years in the North Atlantic climate system was found in [Enfield et al., 2001. Polyakov et al., 2010, Schlesinger and Ramankutty, 1994. Modeling experiments by Delworth and Mann 2000 showed the pronounced 7-8 decades 
spectral maxima. Spectral analysis led Wei and Lohmann 2012 to similar conclusions. Wouters et al. 2012 found the dominance AMOC variability with a scale of 50-60 years. Frankcombe and Dijkstra 2011 and Frankcombe et al. 2010 analyzing the 500-years GFDL CM 2.1 control experiments have shown two broad extremes of variability on the time scales of 2-3 and 5-7 decades. Chylek et al. 2012 came to similar results analyzing the isotope $\delta^{18} \mathrm{O}$ samples of the Greenland ice sheet drilling. MDV of the AMOC index covers the time range from 50 to 200 years [Danabasoglu et al., 2012. Using the Kiel Climatic Model experiments $B a$ et al. 2013 analyzed the AMOC and AMO indexes and showed a roughly 60-year oscillation mode. Empirical Mode Decomposition of the AMO time series also demonstrated the prevalence of MDV [Chen et al., 2016. The same conclusions follow from the analysis of the North Atlantic SST and turbulent surface heat fluxes [Gulev et al., 2013.

In spite of the well-established leading role of the MDV, frequency structure of the North Atlantic climatic indexes still remains ambiguous. Moreover, the existence of spectrum extremes seems doubtful [Cane et al.,2017]. For example, Medhaug and Furevik 2011] found no statistically significant spectral maxima in the AMO and AMOC time series derived from CMIP3 model runs. The same indexes calculated using CMIP5 experiments also demonstrated an absence of the spectral density maxima in any frequency ranges [Zhang and Wang, 2013. Analysis of the AMO variability by $B a$ et al. 2014 and Clement et al. 2015 confirmed these conclusions. Multidecadal and multicentury AMO variability studied by Park and Latif 2008 and Dommenget and Latif 2008] showed the spectral density continuum without pronounced extremes. Lack of the spectral maxima can be explained as a feature of the nonlinear chaotic dynamics or as a linear transform of a stochastic external forcing.

The possible mechanisms of the MDV were in a focus of numerical studies. Several hypotheses explaining mechanisms of the MDV have been proposed. One of them associates the formation of MDV with long-term external forcing, first of all to the aerosol of volcanic origin [Ottera et al., 2010, Booth et al., 2012. However, this idea was criticized later by Zhang et al. 2013 who showed that historical forcing was too weak to serve as the main driver of MDV. Alternative point of view was outlined by Bellomo et al. 2018 who stressed the prevailing role of external factors at the timescale from two decades and longer.

The other concept suggests the leading role of nonlinear processes in the ocean-atmosphere system [Dijkstra and Ghil, 2005, Dijkstra et al., 2008. The proposed mechanism assumes the existence of two quasi-stable stationary states of the Atlantic thermohaline circulation [Cessi, 1994, Rahmstorf, 1995] or SPG [Born and Stocker, 2014, Born et al., [2015]. Dynamical coupling between the atmospheric and oceanic circulation can serve as an alternative mechanism responsible for the lowfrequency climate variability [Wills et al., 2019. Finally, the most accepted hypothesis explains the formation of MDV via response of the highly inertial ocean system to the random atmospheric forcing [Clement et al., 2015, O'Reilly et al., 2016.

The circuit of several cause-and-effect feedbacks argues in favor of describing the process as a damped oscillator [Park and Latif, 2010, Sevellec and Huck, 2015. Intensification of the AMOC means the advection of warm waters into the northern part of the North Atlantic, which leads to the positive AMO phase. Warm SST anomalies in the subpolar North Atlantic region prevent deep winter convection. Weakening of the deep water formation leads to the AMOC decrement. Corresponding deficit of the meridional heat transport implies in turn the development of negative SST anomalies and transition to the negative AMO phase. Cold surface waters in the region of Greenland and Labrador seas initiate formation of the deep waters and increase of the AMOC.

The majority of the Coupled General Circulation Models (GCM) experiments demonstrated that the AMOC index leads AMO by several years. As a rule, the indexes are positively correlated at zero time lag. Gastineau et al. 2016 analyzed the control IPSL-CM5A-LR 500-year climate run and found that the cross-correlation is positive with AMOC leading AMO by 5-12 year. The correlation $r \approx 0.42$ is maxima with the time lag of 8 years. Van Oldenborgh et al. 2009 and Sun et al. 2015 obtained similar estimate of the AMOC and $\mathrm{AMO}$ pair correlation, $r \approx 0.55 \div 0.60$, analyzing the GCM simulations. On the other hand, the COSMOS model generated the AMOC and $\mathrm{AMO}$ indexes changing almost in phase [ $\mathrm{Wei}$ 
and Lohmann, 2012. For five CMIP3 model runs the AMOC-AMO correlation coefficient ranges between 0.1 and 0.5 , with the strongest correlation found when AMOC leads AMO by 0 to 3 years [Day et al., 2012]. Roberts et al. 2013 investigated 10 CMIP5 model runs and demonstrated similar results. The highest correlation was found when AMOC leads by $1-5$ years.

However, there is much complexity in the analysis of the AMOC-AMO connections. The crossspectral analysis carried out by Marini and Frankignoul 2014 displayed that the low-frequency AMOC and $\mathrm{AMO}$ indexes variability resides in phase. Contrary, the phase shift between the two indexes in the model IPSLMC5 was close to $180^{\circ}$ [Marini and Frankignoul, 2014. The estimates derived from 26 CMIP5 models [Muir and Fedorov, 2015] revealed large scatter of the AMOC and AMO characteristics. Zhang and Wang 2013, Wang and Zhang 2013 demonstrated the ambiguous AMOC and AMO relationship, when the correlation in some cases was negative.

What causes the uncertain AMOC-AMO interconnections? Tandon and Kushner 2015, analysing the CMIP3 and CMIP5 control and historical runs, suggested that the external atmospheric forcing can destroy the dynamical AMOCAMO relationships. As a rule, the leading role belongs to the AMOC. An increase of the AMOC index initiates the positive SST anomalies in the subpolar North Atlantic region. However, when an external forcing switches the scenario, the AMO takes the leading role. Now the SST increase induces attenuation of the meridional thermohaline circulation and the correlation of the two indexes becomes negative.

In this study we further develop the idea of Tandon and Kushner 2015. We hypothesize that the atmospheric random forcing is responsible for the MDV formation. In that, the leading role of AMOC is determined by the oceanic system feedbacks. The heat fluxes at the air-sea interface can impact both SST and meridional overturning circulation via intensification of the deep oceanic convection. In case of random excitation of the meridional circulation, the AMOC and AMO indexes are positively correlated. However, the stochastic atmospheric forcing affecting the SST means that correlation between the indexes changes to negative. Theoretical justification of this hypothesis is in the focus of this study.

In the second section, we describe the box stochastic model of the North Atlantic. The third section is devoted to cross-correlation analyses of the model. Finally, we discuss the results and draw the conclusions.

\section{A Simple North Atlantic Model}

Legatt et al. 2012 formulated a box North Atlantic model. Built on the [Marshall et al., 2001] concept, the model associates the excitation of lowfrequency oceanic variability with stochastic atmospheric forcing which is spatially coherent. The main role in the forcing belongs to the North Atlantic Oscillation (NAO) strongly impacting the deep winter convection [McCarthy et al., 2015. On the other hand, NAO also controls the energy exchange between the ocean and the atmosphere forming the large-scale SST anomalies.

Legatt et al. 2012 suggested that the principal factors forming the North Atlantic MDV include the meridional $\psi_{m}$ and horizontal $\psi_{g}$ components of stream function, and the spatially averaged subpolar North Atlantic SST T. The intensities of $\psi_{m}$ and $T$ can serve as the analogues of AMOC and AMO indexes, respectively. We have modified Legatt et al. 2012 model constraining it for simplicity to two equations. In that, the horizontal component of the stream function was neglected. Besides, the dissipative term was added to the evolutionary equation of the meridional steam function. The dimensionless model equations can be written as

$$
\begin{aligned}
\frac{d T}{d t} & =m \psi_{m}-\lambda T+F_{T}(t) \\
\frac{d \psi_{m}}{d t} & =-s T-\alpha \psi_{m}+F_{m}(t)
\end{aligned}
$$

where $F_{T}(t)$ is the atmospheric forcing determined by the net heat surface fluxes, $F_{m}(t)$ is the forcing responsible for the deep water formation and AMOC intensification. We assume the external forcing as a linear function of a stationary Gaussian random process $X(t)=\partial W / \partial t$ (the derivative of the standard Wiener process, $W) ; F_{T}(t)=$ $\sigma_{F_{T}} X(t)$ and $F_{m}(t)=-\sigma_{F_{m}} X(t)$, where $\sigma_{F_{T}}^{2}$ and $\sigma_{F_{m}}^{2}$ are variances of the corresponding fluxes. The 
negative sign in the last relationship is due to the fact that surface heating of the North Atlantic waters damps the deep oceanic convection. The coefficients $\lambda$ and $\alpha$ describe the heat and impulse dissipation, respectively; the parameters $m$ and $s$ are positive and simulate the AMOC-AMO linear feedbacks. Unit of the dimensionless time corresponds to $\sim 4$ years of physical time, the product $m s \approx 3$, [Legatt et al., 2012. Note, that the heat fluxes are considered positive when energy is gained by the ocean (in contrast to [Gulev et al., 2013]).

In general, the model formulation assumes that the main peculiarities of the North Atlantic climate variability can be described in the framework of randomly exited damped oscillator.

\section{Correlation and Cross-Correlation Analyses of AMO and AMOC}

\subsection{Stochastic Forcing of the Meridional Thermohaline Circulation}

In the event of the non-zero meridional thermohaline circulation forcing, i.e. $F_{m}(t) \neq 0, F_{T}(t)=0$ the equation for SST takes the form of the linear damping oscillator

$$
\begin{aligned}
& \frac{d^{2} T}{d t^{2}}+2 a \frac{d T}{d t}+b T=m F_{m}(t) \\
& \frac{d \psi_{m}}{d t}=-s T-\alpha \psi_{m}+F_{m}(t)
\end{aligned}
$$

The coefficients are defined as

$$
2 a=\alpha+\lambda, \quad b=m s+\alpha \lambda
$$

This way, the evolution of the SST is described by the linear differential equation of the second order with a stochastic forcing. The statistically stable solutions of (3) and (4) under the assumptions of $a>0$ and $b-a^{2}>0$ yields (see e.g. [Yaglom, 1987)

$$
T(t)=\int_{0}^{\infty} h_{T}(u) F_{m}(t-u) d u
$$

where $h_{T}(u)$ is weight function

$$
h_{T}(u)=\frac{m}{\beta} \exp (-a u) \sin (\beta u)
$$

$$
\begin{gathered}
\beta=\sqrt{b-a^{2}} \\
\psi_{m}(t)= \\
\int_{0}^{\infty} \exp (-\alpha u)\left(-s T(t-u)+F_{m}(t-u)\right) d u
\end{gathered}
$$

After simplifications (see Appendix A for details), (7) can be presented in the form of the Duhamel integral

$$
\psi_{m}(t)=\int_{0}^{\infty} h_{m}(u) F_{m}(t-u) d u
$$

where $h_{m}(u)$ is a weight function

$$
\begin{gathered}
h_{m}(u)=\exp (-\alpha u)+ \\
\{m s(-\exp (-\alpha u) \beta+\exp (-a u) \times \\
[\beta \cos (\beta u)+(a-\alpha) \sin (\beta u)])\} / \\
\left\{\beta\left((a-\alpha)^{2}+\beta^{2}\right)\right\}
\end{gathered}
$$

The correlation and cross-correlation functions can be written (see Appendix B, equation B2 as

$$
\begin{array}{r}
B_{T}(\tau)=\sigma_{F_{m}}^{2} \int_{0}^{\infty} h_{T}(\xi) h_{T}(\xi+\tau) d \xi \\
B_{\psi_{m}}(\tau)=\sigma_{F_{m}}^{2} \int_{0}^{\infty} h_{m}(\xi) h_{m}(\xi+\tau) d \xi \\
B_{T, \psi_{m}}(\tau)=\sigma_{F_{m}}^{2} \int_{0}^{\infty} h_{T}(\xi) h_{m}(\xi+\tau) d \xi
\end{array}
$$

The weight functions (6) and (8) allow analytical integration of the (9)-(11) The correlation functions can be presented in the following normalized form 


$$
\begin{gathered}
r_{T}(\tau)=\frac{B_{T}(\tau)}{\operatorname{Var}[T]}= \\
\exp (-a|\tau|)\left(\cos (\beta \tau)+\frac{a}{\beta} \sin (\beta|\tau|)\right) \\
r_{\psi_{m}}(\tau)=\frac{B_{\psi_{m}}(\tau)}{\operatorname{Var}\left[\psi_{m}\right]}= \\
\left\{\operatorname { e x p } ( - a | \tau | ) \left(\beta\left(b+\lambda^{2}\right) \cos (\beta \tau)-\right.\right. \\
\left.\left.a\left(b-\lambda^{2}\right) \sin (\beta|\tau|)\right)\right\} /\left\{\beta\left(b+\lambda^{2}\right)\right\}
\end{gathered}
$$

Note, that only random process $T(t)$ is differentiable.

The variances of SST and the meridional component of stream function are defined as

$$
\begin{gathered}
\operatorname{Var}[T]=\frac{\sigma_{m}^{2} m^{2}}{4 a\left(\beta^{2}+a^{2}\right)}=\frac{\sigma_{m}^{2} m^{2}}{4 a b} \\
D\left[\psi_{m}\right]=\frac{\sigma_{m}^{2}\left(b+\lambda^{2}\right)}{4 a b}
\end{gathered}
$$

The normalized cross-correlation function of $T(t)$ and $\psi_{m}(t)$ can be written

$$
\begin{gathered}
r_{T, \psi_{m}}(\tau)=\{\exp (-a|\tau|)(2 \beta \lambda \cos (\beta \tau)- \\
2 b \sin (\beta \tau)+\lambda(\alpha+\lambda) \sin (\beta|\tau|))\} / \\
\left\{2 \beta \sqrt{b+\lambda^{2}}\right\}
\end{gathered}
$$

The normalized cross-correlation function at the zero time lag, $\tau=0$ is described by the relationship

$$
r_{T, \psi_{m}}(\tau=0)=\frac{\lambda}{\sqrt{b+\lambda^{2}}}
$$

Positive correlation of $T(t)$ and $\psi_{m}(t)$ is found in many estimates derived from the GCM numerical simulations. However, the magnitude of the correlation coefficient $r_{T, \psi_{m}}(0)$ can be relatively modest suggesting that the GCM-based estimates of $r_{T, \psi_{m}}(0)$ cannot serve as a strong argument in the AMOC-AMO interrelationship discussion. The derivative of the cross-correlation function by the zero lag, is always negative

$$
\left.\frac{d r_{T, \psi_{m}}}{d \tau}\right|_{\tau=0}=\frac{-b}{\sqrt{b+\lambda^{2}}}
$$

Analysis of the formula (12) provides simple equation defining the time delay corresponding to the largest AMO-AMOC correlation

$$
\tau_{e x}=\frac{-\arccos \left(\frac{\alpha+3 \lambda}{2 \sqrt{m s+2 \lambda(\alpha+\lambda)}}\right)}{\beta}
$$

Applying the parameters values $m s=3, \alpha=$ $\lambda=0.5$ one can obtain an estimate of dimensionless time $\tau_{e x} \approx-0.6$. It corresponds approximately to 2.5 years and, therefore, is in agreement with the GCM simulations (e.g. [Day et al., 2012, Roberts et al., 2013).

\subsection{Stochastic Forcing of the SST}

The second choice for stochastic atmospheric forcing is the direct excitation of the SST. For the sake of simplicity, we will consider here the case when, $F_{T}(t) \neq 0, F_{m}(t)=0$. The normalized correlation functions and variances of the SST and the meridional component of stream function (we apply here upper asterisk to distinguish from the random excitation of the stream function $\psi_{m}$ ) can be represented now as

$$
\begin{gathered}
r_{T}^{*}(\tau)=\left\{\operatorname { e x p } ( - a | \tau | ) \left[\left(b+\alpha^{2}\right) \beta \cos (\beta \tau)-\right.\right. \\
\left.\left.a\left(b-\alpha^{2}\right) \sin (\beta|\tau|)\right]\right\} / \\
\left\{\left(b+\alpha^{2}\right) \beta\right\} \\
r_{\psi_{m}}^{*}(\tau)= \\
\exp (-a|\tau|)\left(\cos (\beta \tau)+\frac{a}{\beta} \sin (\beta|\tau|)\right) \\
\operatorname{Var}^{*}[T]=\frac{\sigma_{T}^{2}\left(b+\alpha^{2}\right)}{4 a b}
\end{gathered}
$$




$$
\operatorname{Var}^{*}\left[\psi_{m}(t)\right]=\frac{\sigma_{T}^{2} s^{2}}{4 a b}
$$

The normalized cross-correlation function takes the form

$$
\begin{gathered}
r_{T, \psi_{m}}^{*}(\tau)=\{-\exp (-a|\tau|)(2 \alpha \beta \cos (\beta \tau)+ \\
2 b \sin (\beta \tau)+\alpha(\alpha+\lambda) \sin (\beta|\tau|))\} / \\
\left\{2 \sqrt{b+\alpha^{2}} \beta\right\}
\end{gathered}
$$

Analysis of the last equation shows that at zero time lag the pair correlation of $T$ and $\psi_{m}$ is always negative

$$
r_{T, \psi_{m}}^{*}(0)=\frac{-\alpha}{\sqrt{b+\alpha^{2}}}
$$

Stochastic forcing of the meridional overturning circulation leads to a positive synchronous AMOCAMO correlation. On the contrary, stochastic forcing of the SST leads to a negative regression. The magnitude of the coefficient can be small and its analysis based on relatively short time series may be problematic. On the other hand, for any stochastic forcing (see also equation (13)) the derivative of the cross-correlation function is negative

$$
\left.\frac{d r_{T, \psi_{m}}^{*}}{d \tau}\right|_{\tau=0}=\frac{-b}{\sqrt{b+\alpha^{2}}}
$$

\section{Discussion}

Some important properties of the North Atlantic MDV can be described in the stochastic model framework (equations (1)-(2)). Particularly, the sign of AMOC-AMO correlation depends on the nature of external forcing. The stochastic excitation of the meridional overturning circulation leads to a positive correlation; the SST random forcing leads to a negative correlation. However, the AMOC-AMO correlation is modest at zero time lag.
The excitation of the meridional overturning circulation in the case of moderate negative time delays $\tau$ leads to a positive correlation of $T(t)$ and $\psi_{m}(t)$ (Figure 1). That provides evidence for AMOC leading role, similar to the results of Sun et al. 2019. The examples of $r_{T, \psi_{m}}(\tau)$ for several different sets of parameters (Figure 1a Figure 1 d ). demonstrate that behaviour of the cross-correlation function is determined by the values of dissipation parameters $\alpha$ and $\lambda$. Figure 1 a corresponds to e-folding time of 4 dimensionless time units or, respectively, to 16 years and is characterised by slowly decaying oscillating behaviour. Increase of the dissipation parameter $\alpha$ and $\lambda$ leads to faster decay of oscillations (Figure 1b,c,d).

The SST stochastic excitation is characterised by important distinctions of cross-correlation function. A comparison between $r_{T, \psi_{m}}^{*}(\tau)$ and $r_{T, \psi_{m}}(\tau)$ reveals some interesting features. For example, if the dissipation parameters $\alpha$ and $\lambda$ are small then the behaviour of $r_{T, \psi_{m}}^{*}(\tau)$ and $r_{T, \psi_{m}}(\tau)$ is similar (Figure 1a,b). Increase of $\alpha$ and $\lambda$ results in significantly different dependences of $r_{T, \psi_{m}}^{*}(\tau)$ and $r_{T, \psi_{m}}(\tau)$ on time delay $\tau$ (Figure 1k,d). The strongest negative cross-correlation $r_{T, \psi_{m}}^{*}(\tau)$ is observed at the positive time lags. Now the crosscorrelation functions $r_{T, \psi_{m}}^{*}(\tau)$ can be interpreted as evidence for the leading role of the AMO. The positive SST anomalies prevent deep water formation and damp the meridional oceanic circulation.

We note that caution should be exercised when interpreting the results of the cross-correlation analysis of the observational and/or GCM modeling data. Often the interpretation of this analysis and especially establishment of the cause-effect relationships seems doubtful and ambiguous. Besides, limited and, as a rule, strongly auto-correlated time series of GCM simulations often cannot guarantee statistically significant estimates. As a consequence, establishment of the physically-based conclusions requires formulation of an adequate background model.

\section{Conclusions}

1. Some important properties of the North Atlantic MDV can be reproduced within the stochastically forced oceanic oscillator model. Stochastic excitation of the meridional over- 

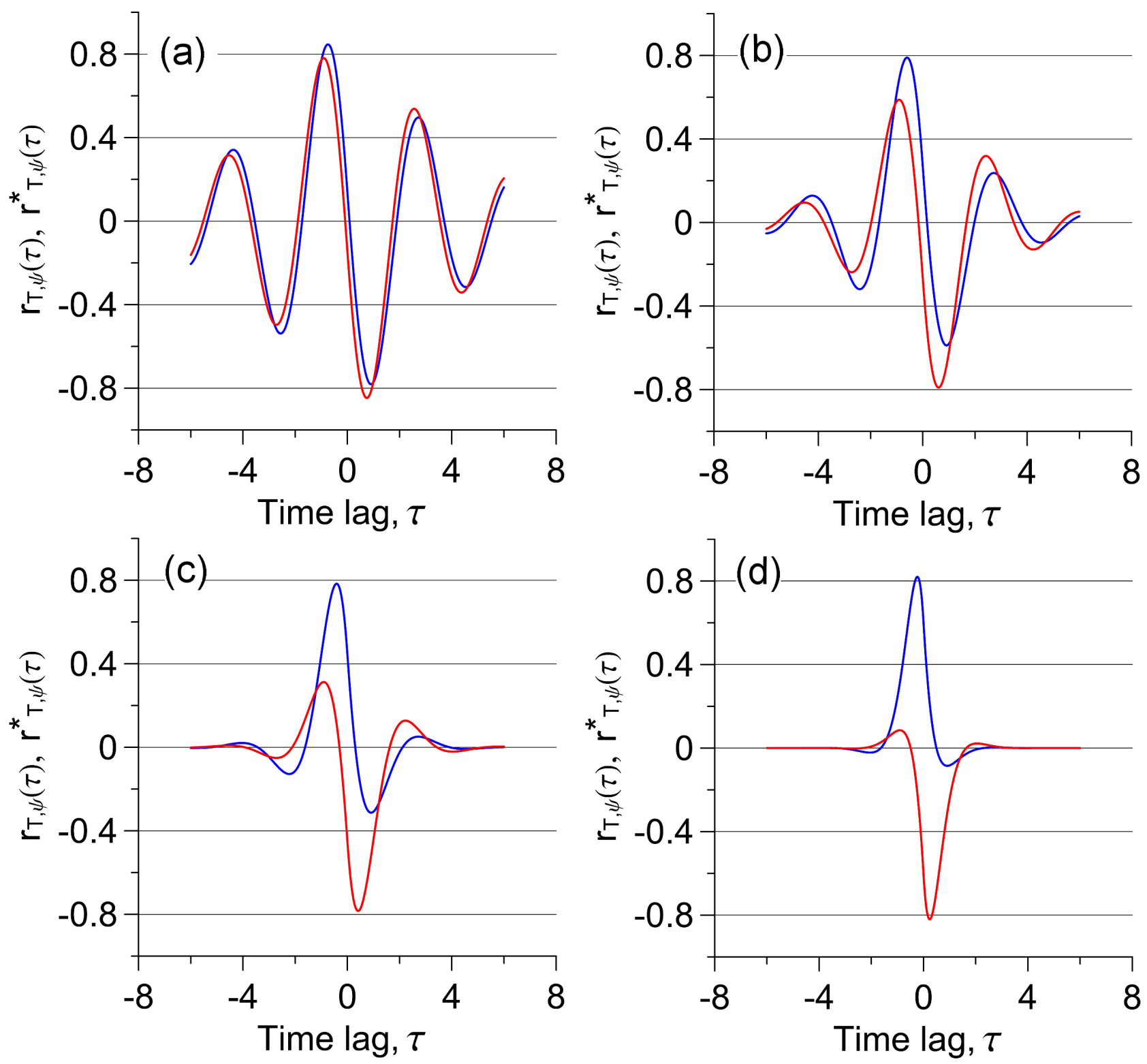

Figure 1. Normalized cross-correlation functions of $T(t)$ and $\psi_{m}(t) . r_{T, \psi_{m}}(\tau)$ (blue line), $r_{T, \psi_{m}}^{*}(\tau)$ (red line). The positive time lags correspond to the leading SST (AMO index). $m s=3$, a) $\alpha=\lambda=0.25$, b) $\alpha=\lambda=0.5$, c) $\alpha=\lambda=1.0$, d) $\alpha=\lambda=2.0$. The parameter values $\alpha=\lambda=0.5$ corresponds to e-folding time equal to 2 units of dimensionless time and, respectively, to 8 years.

turning circulation corresponds to a positive synchronous AMOC-AMO correlation, random forcing of the SST leads to a negative correlation. These differences can explain some discrepancies of the correlation analyses made in the past using GCM outputs.

2. Stochastic excitation of the meridional overturning circulation implies the leading AMOC and stochastic forcing of SST implies the leading AMO. However, in both cases the time derivative of AMOC and AMO crosscorrelation function is always negative at zero time lag.

3. Significant effect of the e-folding time on the AMOC-AMO interrelationship has been found. Cross-correlation function demon- 
strates highly oscillating behaviour in the case of relatively small dissipation coefficients. Decrease of the e-folding time is characterized by almost monotonous decay of the crosscorrelation function.

Acknowledgments. The author thank anonymous reviewer for helpful remarks. The author is also grateful to Igor Polyakov for help and constructive criticism.

\section{Appendix A.}

Using the expression (5) and change of variables, $\xi+u=t^{\prime}$, we can transform equation (7)

$$
\begin{gathered}
\psi_{m}(t)=-s m \int_{0}^{\infty} \exp (-\alpha \xi) \times \\
\int_{\xi}^{\infty} h_{T}\left(t^{\prime}-\xi\right) F_{m}\left(t-t^{\prime}\right) d t^{\prime} d \xi+ \\
\int_{0}^{\infty} \exp (-\alpha \xi) F_{m}(t-\xi) d \xi= \\
-\frac{s m}{\beta} \int_{0}^{\infty} \exp (-\alpha \xi) \int_{\xi}^{\infty} \exp \left(-a\left(t^{\prime}-\xi\right)\right) \times \\
\sin \left(\beta\left(t^{\prime}-\xi\right)\right) F_{m}\left(t-t^{\prime}\right) d t^{\prime} d \xi+ \\
\int_{0}^{\infty} \exp (-\alpha \xi) F_{m}(t-\xi) d \xi
\end{gathered}
$$

The trigonometric identities allow rewriting A1 as

$$
\begin{gathered}
\psi_{m}(t)=-\frac{s m}{\beta} \int_{0}^{\infty} \exp ((a-\alpha) \xi) \times \\
\cos (\beta \xi) \int_{\xi}^{\infty}\left(-a t^{\prime}\right) \sin \left(\beta t^{\prime}\right) F_{m}\left(t-t^{\prime}\right) d t^{\prime} d \xi+
\end{gathered}
$$

$$
\frac{s m}{\beta} \int_{0}^{\infty} \exp ((-\alpha+a) \xi) \sin (\beta \xi) \times
$$$$
\int_{\xi}^{\infty} \exp \left(-a t^{\prime}\right) \cos \left(\beta t^{\prime}\right) F_{m}\left(t-t^{\prime}\right) d t^{\prime} d \xi+
$$$$
\int_{0}^{\infty} \exp (-\alpha \xi) F_{m}(t-\xi) d \xi
$$

Now we can integrate $\mathrm{A} 2$ by part. After some simplifications A2 can be presented in the form of Duhamel integral

$$
\psi_{m}(t)=\int_{0}^{\infty} h_{m}(u) F_{m}(t-u) d u
$$

where $h_{m}(u)$ is a weight function

$$
\begin{gathered}
h_{m}(u)=\exp (-\alpha u)+ \\
\{m s(-\exp (-\alpha u) \beta+\exp (-a u) \times \\
[\beta \cos (\beta u)+(a-\alpha) \sin (\beta u)])\} / \\
\left\{\beta\left((a-\alpha)^{2}+\beta^{2}\right)\right\}
\end{gathered}
$$

\section{Appendix B.}

Let us represent the solutions for the two components $Y(t)$ and $Z(t)$ of the stochastically forced differential equation system in the form of Duhamel integrals

$$
\begin{aligned}
Y(t) & =\int_{0}^{\infty} h_{Y}(u) X(t-u) d u \\
Z(t) & =\int_{0}^{\infty} h_{Z}(u) X(t-u) d u
\end{aligned}
$$


where $h_{Y}(t)$ and $h_{Z}(t)$ are the weight functions of the $Y(t)$ and $Z(t)$, respectively. The input signal $X(t)$ represents stationary stochastic process and is characterized by the correlation function $B_{X}(\tau)$. In the assumptions $M[Y(t)]=M[Z(t)]=0$ crosscorrelation function of the $Y(t)$ and $Z(t)$ can be written as

$$
\begin{gathered}
B_{Y, Z}(\tau)=M[Y(t) Z(t+\tau)]= \\
M\left[\int_{0}^{\infty} \int_{0}^{\infty} h_{Y}(\xi) X(t-\xi) h_{Z}(\eta) \times\right. \\
X(t+\tau-\eta) d \eta d \xi]= \\
\int_{0}^{\infty} h_{Y}(\xi) \int_{0}^{\infty} h_{Z}(\eta) B_{X}(\tau+\xi-\eta) d \eta d \xi
\end{gathered}
$$

Using Parseval's theorem we can write [Bekryaev, 2016 cross-correlation function in the form of convolution integral

$$
\begin{aligned}
& B_{Y, Z}(\tau)=\int_{-\infty}^{\infty} B_{X}(s) \times \\
& \int_{0}^{\infty} h_{Y}(\xi) h_{Z}(\xi+s+\tau) d \xi d s
\end{aligned}
$$

If the input process $X(t)$ is a derivative of the standard Wiener process, $W(t)$, i.e.

$$
X(t)=\sigma_{X}^{2} \frac{d W}{d t}
$$

equation B1 can be represented in a form

$$
B_{Y, Z}(\tau)=\sigma_{X}^{2} \int_{0}^{\infty} h_{Y}(\xi) h_{Z}(\xi+\tau) d \xi
$$

\section{References}

Ba, J., N. S. Keenlyside, W. Park, M. Latif, E. Hawkins, H. Ding (2013), A mechanism for
Atlantic multidecadal variability in the Kiel Climate Model, Clim. Dyn., 41, 2133-2144, Crossref

Ba, J., N. S. Keenlyside, M. Latif, W. Park, H. Ding, K. Lohmann, J. Mignot, M. Menary, O. H. Ottera, B. Wouters, D. Salas y Melia, A. Oka, A. Bellucci, E. Volodin (2014), A multi-model comparison of Atlantic Multidecadal variability, Clim. Dyn., 43, 2333-2348, Crossref

Bekryaev, R. V. (2016), Atmospheric forcing and lowfrequency North Atlantic variability, Proc. Voeikov Main Geophysical Observatory, 581, 41-76.

Bellomo, K., L. N. Murphy, et al. (2018), Historical forcings as main drivers of the Atlantic Multidecadal variability in the CESM large ensemble, Clim. Dyn., 50, 3687-3698, Crossref

Booth, B. B. B., N. J. Dunstone, P. R. Halloran, T. Andrews, N. Bellouin (2012), Aerosols implicated as a prime driver of twentieth-century North Atlantic climate variability, Nature, 484, 228-233, Crossref

Born, A., T. F. Stocker (2014), Two stable equilibria of the Atlantic subpolar gyre, J. Phys. Oceanogr., 44, 246-264, Crossref

Born, A., J. Mignot, T. F. Stocker (2015), Multiple equilibria as a possible mechanism for decadal variability in the North Atlantic ocean, J. Climate., 28, 8907-8922, Crossref

Cane, M. A., A. C. Clement, et al. (2017), Lowpass filtering, heat flux, and Atlantic Multidecadal Variability, J. Climate, 30, 7529-7553, Crossref

Cessi, P. (1994), A simple box model of stochastically forced thermohaline flow, J. Phys. Oceanogr., 24, 1911-1920, Crossref

Chen, H., E. K. Schneider, Z. Wu (2016), Mechanisms of internally generated decadal-to-multidecadal variability of SST in the Atlantic Ocean in a coupled GCM, Clim. Dyn., 46, 1517-1546, Crossref

Chylek, P., C. Folland, L. Frankcombe, H. Dijkstra, G. Lesins, M. Dubey (2012), Greenland ice core evidence for spatial and temporal variability of the Atlantic Multidecadal Oscillations, Geophys. Res. Lett., 39, L09705, Crossref

Clement, A., K. Bellomo, L. N. Murphy, M. A. Cane, T. Mauritsen, G. Radel, B. Stevens (2015), The Atlantic Multidecadal Oscillation without a role for ocean circulation, Science, 350, No. 6258, 320-324, Crossref

Danabasoglu, G., S. G. Yeager, Y.-O. Kwon, J. J. Tribbia, A. S. Phillips, J. W. Hurrell (2012), Variability of the Atlantic Meridional Overturning Circulation in CCSM4, J. Climate, 25, 5153-5172, Crossref

Day, J. J., J. C. Hargreaves, et al. (2012), Sources of multi-decadal variability in Arctic sea ice extent, Environ. Res. Lett., 7, No. 3, 034011, Crossref

Delworth, T. L., M. E. Mann (2000), Observed and simulated multidecadal variability in the Northern Hemisphere, Climate Dynamics, 16, No. 9, 661676, Crossref

Dijkstra, H. A., M. Ghil (2005), Low-frequency vari- 
ability of the large-scale ocean circulation: A dynamical systems approach, Rev. Geophys., 43, RG3002, Crossref

Dijkstra, H. A., L. M. Frankcombe, A. S. v.d.Heydt (2008), A stochastic dynamical systems view of the Atlantic Multidecadal Oscillation, Phil. Trans. $R$. Soc., 366, 2545-2560, Crossref

Dommenget, D., M. Latif (2008), Generation of hyper climate modes, Geophys. Res. Lett., 35, No. L02706, Crossref

Enfield, D. B., A. M. Mestas-Nunez, P. J. Trimble (2001), The Atlantic multidecadal oscillation and its relation to rainfall and river flows in the continental U.S., Geophys. Res. Lett., 28, No. 10, 2077-2080, Crossref

Frankcombe, L. M., A. von der Heydt, H. A. Dijkstra (2010), North Atlantic Multidecadal Climate variability: An Investigation of Dominant Time Scales and Processes, J. Climate., 23, 3626-3638, Crossref

Frankcombe, L. M., H. A. Dijkstra (2011), The role of Atlantic-Arctic exchange in North Atlantic multidecadal climate variability, Geophys. Res. Lett., 38, L16603, Crossref

Gastineau, G., B. L'Heveder, F. Codron, et al. (2016), Mechanisms determining the winter atmospheric response to the Atlantic overturning circulation, J. Climate, 29, 3767-3785, Crossref

Gulev, S. K., M. Latif, N. Keenlyside, W. Park, K. P. Koltermann (2013), North Atlantic Ocean control on surface heat flux on multidecadal timescales, Nature, 499, 464-468, Crossref

Johns, W. E., M. O. Baringer, L. M. Beal, et al. (2011), Continuous, array-based estimates of Atlantic Ocean heat transport at $26.5^{\circ} \mathrm{N}, J$. Climate, 24, 24292449, Crossref

Knight, J. R., R. J. Allan, C. K. Folland, M. Vellinga, M. E. Mann (2005), A signature of persistent natural thermohaline circulation cycles in observed climate, Geophys. Res. Lett., 32, L20708, Crossref

Knight, J. R., C. K. Folland, A. A. Scaife (2006), Climate impacts of the Atlantic Multidecadal Oscillation, Geophys. Res. Lett., 33, L17706, Crossref

Legatt, R., I. V. Polyakov, U. S. Bhatt, X. Zhang, R. V. Bekryaev (2012), North Atlantic variability driven by stochastic forcing in a simple model, Tellus A, 64, 18695, Crossref

McCarthy, G. D., I. D. Haigh, J. J.-M. Hirshi, J. P. Grist, D. A. Smeed (2015), Ocean impact on decadal Atlantic climate variability revealed by sea-level observations, Nature, 521, No. 7553, 508-510, Crossref

Marini, C., C. Frankignoul (2014), An attempt to deconstruct the Atlantic Multidecadal Oscillation, Clim. Dyn., 43, 607-625, Crossref

Marshall, J., Y. Kushnir, D. Battisti, et al. (2001), North Atlantic climate variability: Phenomena, impacts and mechanisms, International Journal of Climatology, 21, 1863-1898, Crossref

Medhaug, I., T. Furevik (2011), North Atlantic 20th century multydecadal variability in coupled climate models: sea surface temperature and ocean overturning circulation, Ocean Science, 7, 389-404, Crossref

Muir, L. C., A. V. Fedorov (2015), How the AMOC affects ocean temperatures on decadal to centennial timescales: the North Atlantic versus an interhemispheric seesaw, Clim. Dyn., 45, 151-160, Crossref d'Orgeville, M., W. R. Peltier (2007), On the Pacific Decadal Oscillation and the Atlantic Multidecadal Oscillation: Might they be related?, Geophys. Res. Lett., 34, L23705, Crossref

O'Reilly, C. H., M. Huber, T. Woollings, L. Zanna (2016), The signature of low-frequency oceanic forcing in the Atlantic Multidecadal Oscillation, Geophys. Res. Lett., 43, 2810-2818, Crossref

Ottera, O. H., M. Bentsen, H. Drange, L. Suo (2010), External forcing as a metronome for Atlantic multidecadal variability, Nature Geoscience, 3, 688694, Crossref

Park, W., M. Latif (2008), Multidecadal and multicentennial variability of the meridional overturning circulation, Geophys. Res. Lett., 35, L22703, Crossref

Park, W., M. Latif (2010), Pacific and Atlantic Multidecadal variability in the Kiel Climate Model, Geophys. Res. Lett., 37, L24702, Crossref

Polyakov, I. V., V. A. Alexeev, U. S. Bhatt, et al. (2010), North Atlantic warming: patterns of longterm trend and multidecadal variability, Clim. Dyn., 34, 439-457, Crossref

Rahmstorf, S. (1995), Bifurcations of the Atlantic thermohaline circulation in response to changes in the hydrological cycle, Nature, 378, 145-149, Crossref

Roberts, C. D., F. K. Garry, L. C. Jackson (2013), A multimodel study of sea surface temperature and subsurface density fingerprints of the Atlantic meridional overturning circulation, J. Climate, 26, 91559174, Crossref

Schlesinger, M. E., N. Ramankutty (1994), An oscillation in the global climate system of period 65 70 years, Nature, 367, 723-726, Crossref

Sevellec, F., T. Huck (2015), Theoretical investigation of the Atlantic Multidecadal Oscillation, $J$. Phys. Oceanogr., 45, 2189-2208, Crossref

Sun, C., J. Li, F.-F. Jin (2015), A delayed oscillator model for the quasi-periodic multidecadal variability of the NAO, Climate Dynamics, 45, 2083-2099, Crossref

Sun, C., J. Li, F. Kucharski, J. Xue, X. Li (2019), Contrasting spatial structures of Atlantic Multidecadal Oscillation between observations and slab ocean model simulations, Climate Dynamics, 52, No. 3-4, 1395-1411, Crossref

Tandon, N. F., P. J. Kushner (2015), Does external forcing interfere with the AMOC's influence on North Atlantic sea surface temperature?, J. Climate, 28, 6309-6323, Crossref

Trenberth, K. E., D. J. Shea (2006), Atlantic hurricanes and natural variability in 2005, Geophys. 
Res. Lett., 33, L12704, Crossref

Ushakov, K. V., R. A. Ibrayev (2018), Assessment of mean world ocean meridional heat transport characteristics by a high-resolution model, Russ. J. Earth. Sci., 18, ES1004, Crossref

Van Oldenborgh, G. J., L. A. te Raa, H. A. Dijkstra, S. Y. Philip (2009), Frequency- or amplitudedependent effects of the Atlantic meridional overturning on the tropical Pacific Ocean, Ocean Sci., 5, 293-301, Crossref

Wang, C., L. Zhang (2013), Multidecadal ocean temperature and salinity variability in the tropical North Atlantic: Linking with the AMO, AMOC, and subtropical cell, J. Climate, 26, 6137-6162, Crossref

Wei, W., G. Lohmann (2012), Simulated Atlantic Multidecadal Oscillation during the Holocene, J. Climate, 25, 6989-7002, Crossref

Wills, R. C. J., K. C. Armour, D. S. Battisti, D. L. Hartmann (2019), Ocean-atmosphere dynamical coupling fundamental to the Atlantic Multidecadal Oscillation, J. Climate, 32, 251-272, Crossref
Wouters, B., S. Drijfhout, W. Hazeleger (2012), Interdecadal North-Atlantic meridional overturning circulation variability in EC_EARTH, Clim. Dyn., 39, 2695-2712, Crossref

Zhang, L., C. Wang (2013), Multidecadal North Atlantic sea surface temperature and Atlantic meridional overturning circulation variability in CMIP5 historical simulations, J. Geophys. Res. Oceans, 118, 5772-5791, Crossref

Zhang, R., T. L. Delworth, R. Sutton, et al. (2013), Have aerosols caused the observed Atlantic Multidecadal Variability?, J. Atmos. Sci., 70, 1135-1144, Crossref

Yaglom, A. M. (1987), Correlation Theory of Stationary and Related Random Functions, Volume I: Basic Results, Springer Series in Statistics, p. XIV, 526 pp. Springer, Dordrecht.

\section{Corresponding author:}

Roman V. Bekryaev, Earth Science Institute, St. Petersburg State University, St. Petersburg, Russia. (bekryaev@mail.ru) 